\title{
Associations between parental feeding practices, problem food behaviours and dietary intake in New Zealand overweight children aged $4-8$ years
}

\author{
Jillian J Haszard ', Paula ML Skidmore ${ }^{1}$, Sheila M Williams ${ }^{2}$ and Rachael W Taylor ${ }^{3, *}$ \\ ${ }^{1}$ Department of Human Nutrition, University of Otago, Dunedin, New Zealand: ${ }^{2}$ Department of Preventive and Social \\ Medicine, University of Otago, Dunedin, New Zealand: ${ }^{3}$ Department of Medicine, University of Otago, PO Box 56, \\ Dunedin 9054, New Zealand
}

Submitted 30 0ctober 2013: Final revision received 7 May 2014: Accepted 14 May 2014: First published online 23 June 2014

\begin{abstract}
Objective: Parents report that children's eating behaviours are a major barrier to providing them with a healthy diet. Links between problem eating behaviours and parental feeding practices are not well established and have not previously been examined in overweight children. The aim of the present study was to assess associations between problem food behaviours, dietary intake and parental feeding practices of overweight children aged $4-8$ years.

Design: Participants were recruited for a lifestyle intervention ( $n$ 203). At baseline, children's BMI was measured and parents completed comprehensive questionnaires about the feeding practices they used, the problem food behaviours their children exhibited and the foods their child consumed. A fussy eating scale was developed and associations were determined using correlations and regression analysis, including interactions.

Setting: Dunedin, New Zealand.

Subjects: Overweight children aged 4-8 years.

Results: Healthy eating guidance and monitoring by parents were related to the consumption of fewer unhealthy foods $(B=-0 \cdot 4, P=0 \cdot 001$ and $B=-0 \cdot 4$, $P<0 \cdot 001$ ). Conversely, a lack of parental control (child control) was related to a higher intake of unhealthy foods $(B=0.5, P<0.001)$. Parents of children who were fussy eaters monitored their child's food intake less $(P<0 \cdot 001)$ and allowed the child more freedom over what he/she ate $(P<0 \cdot 001)$. These children consumed fewer fruit and vegetables than those who were not fussy eaters $(P<0.001)$. However, fussy eaters with food-restrictive parents ate more fruit and vegetables $(B=2 \cdot 9, P<0 \cdot 001)$.

Conclusions: These results suggest that a more structured food environment might be beneficial for the diet and food behaviours of young overweight children.
\end{abstract}

A healthy diet is an important factor in the treatment and prevention of obesity in childhood $^{(1,2)}$, yet parents report many issues with providing healthy food for their children $^{(3-6)}$. In particular, they describe child resistance and picky eating as challenges they find hard to overcome ${ }^{(3,5-8)}$. Parents want to know how to feed their children in a way that brings these problem behaviours under control and results in a healthier $\operatorname{diet}^{(4,7,9)}$.

To be able to advise parents how to appropriately feed their children in a healthy way that might overcome, reduce or prevent problem food behaviours, a clear understanding of the relationships between parental feeding practices and problem eating behaviours must first be established. While fussy eating has previously been linked with various parental feeding practices, inconsistent results are clearly apparent ${ }^{(10-15)}$. Furthermore, most of these investigations have used a questionnaire limited to measuring controlling feeding practices ${ }^{(16)}$, restricting the current perspective to only this aspect.

To date, there is evidence to suggest that restrictive feeding practices are associated with both fussy and emotional eating ${ }^{(10,11,15)}$, although not all studies have shown a relationship ${ }^{(12,13,15)}$. Restriction might also encourage secretive eating behaviours such as food hiding ${ }^{(17)}$. Greater food fussiness has been associated with greater parental pressure to eat ${ }^{(11,12)}$. However, child control of food 
intake, presumably the antithesis of restriction and pressure, has also been associated with overeating ${ }^{(18)}$ and could cause or exacerbate food fussiness ${ }^{(19)}$. Because of the limited range of feeding practices examined, more complete measures of feeding practices need to be utilised to gain a broader understanding of the dynamics of these relationships. Only one study appears to have used a more comprehensive assessment of feeding practices ${ }^{(13)}$ and determined that fussy eating was not related to restriction or pressure, but instead negatively associated with monitoring, providing balance and variety in the diet and a healthy food environment.

Parents want to know how to feed their children healthily. With child obesity of prime concern, it is of interest to examine the links between parent feeding and child eating behaviours in overweight children. The aim of the present study is to examine the associations between parental feeding practices, dietary intake and a range of problem food behaviours in overweight 4-8-year-old New Zealand children. Broad measures are used and the moderating effect of fussy eating on the relationships between parental feeding practices and dietary intake is examined.

\section{Methods}

\section{Participants}

The MInT (Motivational Interviewing and Treatment) Study ${ }^{(20)}$ was a two-phase randomised controlled trial in which Phase 1 screened for overweight in children aged 4-8 years. Phase 2 was a two-year, family-based intervention to prevent excessive weight gain in the children identified as overweight ${ }^{(20)}$. Data from the baseline measures of Phase 2 were used in the present analysis.

Participants were recruited from nine primary care practices and two secondary care clinics in Dunedin, New Zealand, between March 2010 and August 2011. Parents were invited to bring their child to a health check at which the child's height, weight, body composition and blood pressure were measured while the parent completed several questionnaires. If the child was identified as overweight (BMI $\geq 85$ th percentile ${ }^{(21)}$ ) the parent was invited back to a follow-up appointment two weeks after the health check at which he/she was invited into the second phase of the MInT Study, i.e. the two-year lifestyle intervention. If he/she agreed to this, the parent attended a baseline appointment for Phase 2 where he/she completed further questionnaires. The study was conducted according to the guidelines laid down in the Declaration of Helsinki and all procedures involving human subjects were approved by the Lower South Regional Ethics Committee (LRS/09/09/039). Informed written consent was obtained from a parent or guardian of all participating children.

Parents answered questions on maternal education and child ethnicity using the New Zealand 2006 census questions ${ }^{(22)}$. Maternal education was subsequently categorised into: some secondary; completed secondary; tertiary qualification (not university degree); university degree; and other. Participants were able to identify with more than one ethnic group and if so, ethnicity was prioritised as recommended by Statistics New Zealand in the following order of priority: Māori; Pacific Island; Asian; New Zealand European; and Other.

Socio-economic status (SES) was determined using the New Zealand deprivation index 2006 (NZDep2006) ${ }^{(23)}$, which used the participant's home address to identify the level of deprivation in that neighbourhood on a scale from 1 to 10. From this, SES was categorised as high (low deprivation, NZDep2006 1-3), medium (NZDep2006 4-7) or low (high deprivation, NZDep2006 8-10).

\section{Measures}

Children's height was measured to the nearest $0 \cdot 1 \mathrm{~cm}$ with a portable Leicester Height Measure (Invicta Plastics Ltd, Leicester, UK) and weight was measured to the nearest $0 \cdot 1 \mathrm{~kg}$ using digital scales (Tanita BC-418). Measures were obtained in duplicate and averages calculated. BMI was calculated and the Centers for Disease Control and Prevention's growth charts ${ }^{(21)}$ used to determine $Z$-scores. Children were categorised as normal weight $(\mathrm{BMI}<85$ th percentile), overweight ( 85 th percentile $\leq \mathrm{BMI}<95$ th percentile) or obese (BMI $\geq 95$ th percentile). Only children identified as overweight or obese were included in the present analysis.

Parental feeding practices were assessed with the Comprehensive Feeding Practices Questionnaire $(\mathrm{CFPQ})^{(24)}$ using the five factors determined by a thorough factor analysis in the full (including normal weight) MInT Study sample of 1093 children $^{(25)}$; namely, 'healthy eating guidance' (how much a parent teaches, models and encourages healthy eating), 'monitoring' (how much a parent keeps track of the unhealthy food that the child consumes), 'parent pressure' (how much the parent pressures the child to eat or uses food to elicit good behaviour), 'restriction' (how much the parent restricts the child's food intake) and 'child control' (how much the child determines which food is consumed and when). The CFPQ is a forty-nine-item questionnaire and answers were given on 5-point response scales from 'never' to 'always' for questions and from 'disagree' to 'agree' for statements $^{(24)}$. Participant scores were calculated as the average of all items in the subscale. If one answer in a subscale was missing, this was imputed by the average of the other items; if more than one item was missing then the subscale was coded as missing.

Dietary intake was assessed using three scales from the Children's Dietary Questionnaire (CDQ) ${ }^{(26)}$. The CDQ consists of twenty-nine questions about the child's intakes of fruit and vegetables, sweet drinks, dairy foods and noncore foods. Questions cover both variety and frequency of consumption over the past $24 \mathrm{~h}$ and $7 \mathrm{~d}$. Non-core foods 
consist of items such as confectionery, biscuits, chips and takeaways. Data are collated to form scores for fruit and vegetables (recommended score is $\geq 14$ ), sweetened beverages (recommended score $\leq 1$ ) and non-core foods

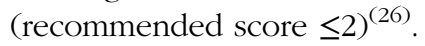

Problem behaviours in overweight children were measured using the Lifestyle Behaviour Checklist (LBC) ${ }^{(27)}$. Only the questions related to problem food behaviours were used in the present analysis (questions 1-15) and included items such as whinging about food, refusing to eat food, requesting food continuously, sneaking food and eating food to comfort themselves. Responses to how much these behaviours had been problems in the last month were recorded on a 7-point response scale from 'not at all' to 'very much'.

Fussy eating was assessed using the average of questions $4-8$ of the LBC; i.e. refusing to eat foods and exhibiting resistance or difficult behaviour around food (whinging, yelling, arguing or having a tantrum). This score was named 'fussy eating' and participants were then grouped into two groups: fussy eaters (having a fussy eating score greater than the mean) and non-fussy eaters (having a fussy eating score less than or equal to the mean). The mean was used to split the groups rather than the median so that only those participants who were exhibiting greater than average fussy behaviour would be classed as fussy.

\section{Analysis}

Means, standard deviations, medians and ranges were calculated for each of the dietary intake scores and the problem food behaviours. Pair-wise correlations were calculated between the food behaviour problem questions and parental feeding practices and dietary intake scores.

Means and standard deviations for the five feeding practices, dietary intake scores and BMI $Z$-scores were calculated for both fussy eaters and non-fussy eaters and two-tailed $t$ tests determined if the means were significantly different, using a significance level of $P<0 \cdot 05$.

Regression analyses for the dietary intake scores were undertaken for each of the feeding practices. These were adjusted for ethnicity, SES, sex and age and also for clusters present when a family had more than one child in the study. Non-standardised $(B)$ regression coefficients, 95\% confidence intervals and $P$ values were calculated. To determine if fussy eating moderated the relationships between dietary intake and parental feeding practices, these regressions were also undertaken with an interaction term. If the interaction term was significant, then the regressions were stratified for fussy and non-fussy eaters. All analyses were undertaken with the statistical software package Stata $12 \cdot 0$.

\section{Missing data}

As the questionnaires were completed online, there was very little missing data. Six participants had missing data for SES and were therefore excluded list-wise from the final regression analyses. For those who were missing only one item from a feeding practices subscale, missing values were imputed from the average of the answered questions in the scale. There was only one participant who had more than one unanswered question for two of the feeding practices scales (healthy eating guidance and parent pressure) and this participant was excluded list-wise from analyses involving these scales.

\section{Results}

\section{Sample characteristics}

Two hundred and three children entered Phase 2 of the MInT Study and had parents who completed all of the baseline measures. In this sample of overweight children, $55 \%$ were female and the average age was 6.4 (SD 1.4) years, with a range of $4 \cdot 1-9 \cdot 0$ years. In total there were 193 families in Phase 2, eight families had two children and one family had three children enrolled in the study. Table 1 shows further demographic information. The sample was slightly over-representative of Māori (the indigenous people of New Zealand) when compared with national data (15\% of the population) and underrepresentative of Pacific Island (7\%) and Asian (9\%) ethnicities ${ }^{(22)}$. However, this sample demonstrated greater diversity than is seen in the local area population and was a sample of overweight children, whose demographics differ from national figures. There were good proportions

Table 1 Baseline characteristics of the study participants; overweight children aged $4-8$ years ( $n$ 203), Dunedin, New Zealand, MInT (Motivational Interviewing and Treatment) Study

\begin{tabular}{|c|c|c|}
\hline & $n$ & $\%$ \\
\hline \multicolumn{3}{|l|}{ Ethnicity } \\
\hline New Zealand European & 144 & $70 \cdot 9$ \\
\hline Māori & 38 & $18 \cdot 7$ \\
\hline Pacific Island & 11 & 5.4 \\
\hline Asian & 6 & $3 \cdot 0$ \\
\hline Other† & 4 & $2 \cdot 0$ \\
\hline \multicolumn{3}{|l|}{ Socio-economic status } \\
\hline Low & 49 & 24.9 \\
\hline Medium & 72 & $36 \cdot 6$ \\
\hline High & 76 & 38.6 \\
\hline \multicolumn{3}{|l|}{ Maternal education } \\
\hline Some secondary & 60 & $29 \cdot 6$ \\
\hline Completed secondary & 14 & $6 \cdot 9$ \\
\hline Tertiary qualificationł & 39 & $19 \cdot 2$ \\
\hline University degree & 75 & $37 \cdot 0$ \\
\hline Other§ & 15 & $7 \cdot 4$ \\
\hline \multicolumn{3}{|l|}{ Child weight status } \\
\hline Overweightll & 121 & $60 \cdot 0$ \\
\hline Obeseף & 82 & $40 \cdot 0$ \\
\hline
\end{tabular}

†One missing, two 'New Zealanders' (not European) and one Brazilian. $\ddagger$ Not university degree.

§Four missing, with the remaining indicating certificates in cooking, massage, unit standards or correspondence courses.

$\| 85$ th percentile $\leq \mathrm{BMI}<95$ th percentile ${ }^{(21)}$.

$\left\lceil\mathrm{BMI} \geq 95\right.$ th percentile ${ }^{(21)}$. 
Table 2 Descriptive statistics for dietary intake and problem food behaviours among overweight children aged 4-8 years ( $n$ 203), Dunedin, New Zealand, MInT (Motivational Interviewing and Treatment) Study

\begin{tabular}{|c|c|c|c|c|c|c|}
\hline Variable & Mean & SD & Median & $\begin{array}{l}\text { Percentage of children } \\
\text { above the mean }\end{array}$ & Range & $\begin{array}{c}\text { Maximum } \\
\text { possible score }\end{array}$ \\
\hline Fruit and vegetable intake score & $13 \cdot 7$ & $4 \cdot 1$ & $14 \cdot 1$ & 55 & $2 \cdot 4-23 \cdot 1$ & 28 \\
\hline Non-core food intake score & 2.5 & 1.0 & 2.4 & 48 & $0-6 \cdot 0$ & $10 \cdot 3$ \\
\hline Sweetened beverage intake score & 0.9 & $1 \cdot 2$ & 0.3 & 45 & $0-5.9$ & 5.9 \\
\hline Eats too quickly & $2 \cdot 2$ & $1 \cdot \overline{7}$ & 1 & 31 & $1-7$ & 7 \\
\hline Eats too much & 2.7 & 1.7 & 2 & 44 & $1-7$ & 7 \\
\hline Eats unhealthy snacks & 2.9 & $1 \cdot 3$ & 3 & 52 & $1-6$ & 7 \\
\hline Whinges or whines about food & 3.5 & 1.9 & 3 & 44 & $1-7$ & 7 \\
\hline Yells about food & $1 \cdot 6$ & $1 \cdot 1$ & 1 & 29 & $1-6$ & 7 \\
\hline Throws a tantrum about food & $1 \cdot 8$ & $1 \cdot 2$ & 1 & 40 & $1-7$ & 7 \\
\hline Refuses to eat certain foods & $2 \cdot 9$ & 1.9 & 2 & 43 & $1-7$ & 7 \\
\hline Argues about food & $2 \cdot 6$ & 1.6 & 2 & 39 & $1-7$ & 7 \\
\hline Demands extra helpings & 1.9 & $1 \cdot 3$ & 1 & 46 & $1-7$ & 7 \\
\hline Requests food continuously between meals & 2.9 & $1 \cdot 8$ & 2 & 46 & $1-7$ & 7 \\
\hline Demands food when on outings & $2 \cdot 4$ & 1.5 & 2 & 33 & $1-7$ & 7 \\
\hline Sneaks food & $1 \cdot 8$ & $1 \cdot 2$ & 1 & 42 & $1-7$ & 7 \\
\hline Hides food & $1 \cdot 2$ & 0.6 & 1 & 11 & $1-6$ & 7 \\
\hline Steals food & $1 \cdot 0$ & 0.3 & 1 & 1 & $1-4$ & 7 \\
\hline Eats food to comfort themselves & $1 \cdot 3$ & 0.8 & 1 & 16 & $1-6$ & 7 \\
\hline
\end{tabular}

Table 3 Pair-wise correlations between problem food behaviours, parental feeding practices and dietary intake among overweight children aged 4-8 years ( $n$ 203), Dunedin, New Zealand, MInT (Motivational Interviewing and Treatment) Study

\begin{tabular}{|c|c|c|c|c|c|c|c|c|}
\hline & \multicolumn{5}{|c|}{ Parental feeding practices } & \multicolumn{3}{|c|}{ Dietary intake } \\
\hline & $\begin{array}{l}\text { Healthy eating } \\
\text { guidance }\end{array}$ & Monitoring & $\begin{array}{l}\text { Parent } \\
\text { pressure }\end{array}$ & Restriction & $\begin{array}{l}\text { Child } \\
\text { control }\end{array}$ & $\begin{array}{l}\text { Fruit and } \\
\text { vegetables }\end{array}$ & $\begin{array}{l}\text { Non-core } \\
\text { foods }\end{array}$ & $\begin{array}{l}\text { Sweetened } \\
\text { beverages }\end{array}$ \\
\hline Eats too quickly & 0.02 & 0.09 & $-0.23^{\star \star}$ & $0.25^{\star \star}$ & -0.02 & 0.01 & $-0 \cdot 17^{\star}$ & -0.04 \\
\hline Eats too much & -0.06 & -0.03 & $-0 \cdot 21^{\star *}$ & $0.48^{\star \star}$ & 0.03 & -0.01 & -0.08 & 0.10 \\
\hline Eats unhealthy snacks & $-0.22^{\star *}$ & $-0.33^{\star *}$ & 0.12 & 0.02 & $0.39^{*}$ & $-0 \cdot 40^{\star *}$ & $0.30^{\star \star}$ & $0.17^{*}$ \\
\hline Whinges or whines about food & -0.06 & $-0.22^{\star \star}$ & $0.22^{\star *}$ & 0.13 & $0 \cdot 18^{*}$ & -0.07 & 0.13 & 0.09 \\
\hline Yells about food & -0.06 & $-0 \cdot 19^{\star \star}$ & 0.12 & $0 \cdot 17^{*}$ & $0 \cdot 17^{\star}$ & -0.08 & $0 \cdot 16^{\star}$ & $0.26^{\star *}$ \\
\hline Throws a tantrum about food & 0.01 & $-0.15^{\star}$ & 0.11 & $0.15^{\star}$ & 0.10 & $-0 \cdot 15^{*}$ & 0.11 & $0.14^{\star}$ \\
\hline Refuses to eat certain foods & -0.03 & $-0 \cdot 28^{\star *}$ & $0.27^{\star \star}$ & 0.01 & $0.34^{\star *}$ & $-0 \cdot 30^{\star *}$ & 0.10 & $0.15^{*}$ \\
\hline Argues about food & -0.07 & -0.13 & 0.11 & $0.16^{*}$ & $0 \cdot 16^{*}$ & -0.11 & 0.01 & 0.06 \\
\hline Demands extra helpings & -0.01 & -0.06 & -0.07 & 0.12 & 0.13 & -0.01 & -0.02 & $0.17^{\star}$ \\
\hline $\begin{array}{l}\text { Requests food continuously } \\
\text { between meals }\end{array}$ & $-0 \cdot 14^{*}$ & $-0 \cdot 15^{\star}$ & 0.04 & $0.20^{\star *}$ & $0 \cdot 16^{*}$ & $-0 \cdot 10$ & $0.16^{\star}$ & 0.08 \\
\hline Demands food when on outings & -0.02 & -0.04 & 0.08 & 0.14 & 0.06 & $-0 \cdot 11$ & -0.05 & 0.01 \\
\hline Sneaks food & -0.03 & -0.09 & $0.14^{*}$ & 0.12 & 0.06 & -0.03 & $0.14^{*}$ & $0 \cdot 10$ \\
\hline Hides food & 0.02 & -0.06 & 0.05 & 0.10 & -0.01 & 0.05 & 0.00 & $0.16^{\star}$ \\
\hline Eats food to comfort themselves & -0.05 & -0.09 & -0.11 & $0.19^{\star *}$ & -0.03 & -0.05 & -0.08 & 0.04 \\
\hline
\end{tabular}

${ }^{*} P<0.05,{ }^{* *} P<0.01$.

of low SES (25\%) and low maternal education (30\%) in this sample, capturing a diverse range of children. Forty per cent of the sample was classified as obese and $60 \%$ as overweight.

\section{Dietary intake and problem food behaviours}

Table 2 demonstrates descriptive statistics for the dietary intake and problem food behaviours in this sample. Just over half $(53 \%)$ the sample achieved the recommended intake for fruit and vegetables (i.e. score of $\geq 14)^{(26)}$. Even fewer children met the recommendation for non-core food intake (37\%), but 130 participants ( $64 \%$ of the sample) were consuming sweet drinks within recommended amounts (i.e. score of $\leq 1$ ).

Different problem food behaviours had different distributions, with whinging and arguing about food, refusing foods, requesting and demanding food having higher means than the other problem behaviours. As only three participants scored $>1$ (minimum value) on the stealing food question, this question was removed from subsequent analyses.

\section{Problem food behaviours, feeding practices and dietary intake}

As shown in Table 3, both eating too quickly and eating too much were linked with lower levels of parent pressure and higher levels of restriction. Eating unhealthy snack foods was related to less healthy eating guidance and monitoring and more child control. Fussy eating behaviours such as whinging, yelling or refusing food were associated with less monitoring and more parent pressure, restriction and child control, and also with the 
Table 4 BMI Z-scores, parental feeding practices and dietary intake scores, for fussy eaters compared with non-fussy eaters, among overweight children aged $4-8$ years ( $n$ 203), Dunedin, New Zealand, MInT (Motivational Interviewing and Treatment) Study

\begin{tabular}{|c|c|c|c|c|c|}
\hline & \multicolumn{2}{|c|}{$\begin{array}{l}\text { Non-fussy eaters } \\
(n 129)\end{array}$} & \multicolumn{2}{|c|}{$\begin{array}{l}\text { Fussy eaters } \\
(n \text { 74) }\end{array}$} & \multirow[b]{2}{*}{$P$} \\
\hline & Mean & $\mathrm{SD}$ & Mean & SD & \\
\hline BMI Z-score & 1.6 & 0.5 & $1 \cdot 7$ & 0.4 & 0.094 \\
\hline Healthy eating guidance $\dagger$ & 4.3 & 0.5 & $4 \cdot 2$ & 0.6 & 0.079 \\
\hline Monitoringt & 4.3 & 0.7 & 3.9 & 0.8 & $<0.001$ \\
\hline Parent pressure $†$ & $2 \cdot 4$ & 0.8 & $2 \cdot 7$ & 0.8 & 0.009 \\
\hline Restriction† & $2 \cdot 1$ & 0.7 & $2 \cdot 3$ & 0.6 & 0.067 \\
\hline Child control† & $2 \cdot 2$ & 0.6 & 2.5 & 0.7 & $<0.001$ \\
\hline Fruit and vegetable intake & 14.5 & 4.0 & $12 \cdot 3$ & 3.9 & $<0.001$ \\
\hline Non-core food intake & $2 \cdot 4$ & 1.0 & 2.6 & 0.9 & 0.288 \\
\hline Sweetened beverage intake & 0.9 & 1.1 & 1.0 & 1.4 & 0.409 \\
\hline
\end{tabular}

†Scores from the Comprehensive Feeding Practices Questionnaire (possible range: 1-5).

$\ddagger$ Scores from the Children’s Dietary Questionnaire.

Table 5 Linear regression results $†$ for dietary intake scores and feeding practices among overweight children aged 4-8 years ( $n$ 197), Dunedin, New Zealand, MInT (Motivational Interviewing and Treatment) Study

\begin{tabular}{|c|c|c|c|}
\hline Feeding practice & Regression coefficient, $B$ & $95 \% \mathrm{Cl}$ & $P$ value \\
\hline \multicolumn{4}{|l|}{ Fruit and vegetable intake $\ddagger$} \\
\hline Healthy eating guidance & 1.5 & $0.5,2.5$ & 0.002 \\
\hline Monitoring & 0.5 & $-0.3,1.3$ & 0.215 \\
\hline Parent pressure & -0.1 & $-0.9,0.6$ & 0.579 \\
\hline Restriction & 0.6 & $-0.3,1.4$ & 0.184 \\
\hline Child control & $-1 \cdot 1$ & $-1.9,-0.2$ & 0.013 \\
\hline \multicolumn{4}{|l|}{ Non-core food intake } \\
\hline Healthy eating guidance & -0.4 & $-0.7,-0.2$ & 0.001 \\
\hline Monitoring & -0.4 & $-0.6,-0.3$ & $<0.001$ \\
\hline Parent pressure & 0.2 & $0.1,0.4$ & 0.074 \\
\hline Restriction & -0.2 & $-0.4,0.0$ & 0.059 \\
\hline Child control & 0.5 & $0.3,0.7$ & $<0.001$ \\
\hline \multicolumn{4}{|l|}{ Sweetened beverage intake } \\
\hline Healthy eating guidance & -0.5 & $-0.8,-0.2$ & 0.001 \\
\hline Monitoring & -0.5 & $-0.7,-0.3$ & $<0.001$ \\
\hline Parent pressure & 0.2 & $0.0,0.4$ & 0.062 \\
\hline Restriction & 0.2 & $-0.1,0.4$ & 0.116 \\
\hline Child control & 0.2 & $-0.1,0.5$ & 0.129 \\
\hline
\end{tabular}

†Adjusted for ethnicity, socio-economic status, age and sex and also family clusters ( $n 196$ for healthy eating guidance and parent pressure analyses).

¥Scores from the Children's Dietary Questionnaire.

consumption of fewer fruit and vegetables and more sweet drinks. More frequent food requests from the child were associated with lower levels of healthy eating guidance and monitoring from the parent and more restrictive or child-controlled feeding practices. Sneaking food was related to greater parent pressure and non-core food intake by the child, while hiding food was related only to greater sweetened beverage intake. Meanwhile children who were more likely to eat to comfort themselves when feeling let down or depressed were also exposed to greater levels of restrictive feeding practices from parents.

\section{Fussy eating}

The reliability coefficient (Cronbach's $\alpha$ ) for the fussy eating scale (questions 4-8 from the LBC) was 0.84, indicating good internal consistency. The mean score for fussy eating was 2.44 (SD $1 \cdot 2$ ) with a range of $1-6 \cdot 8$. Seventy-four children (out of 203) were categorised as fussy eaters, by having a fussy eating score greater than the mean. Parents of fussy eaters reported higher levels of parent pressure and child control and also less monitoring of food intake (Table 4). Fussy eaters also consumed less fruit and vegetables than non-fussy eaters, although reported noncore food intake did not differ.

Table 5 presents the dietary intake regression coefficients for feeding practices in the whole sample, adjusted for ethnicity, SES, sex and age. In the main, these adjustments strengthened the associations with foods but not sweet drinks (data not shown). This showed that healthy eating guidance was associated with greater fruit and vegetable consumption $(B=1.5)$ and lower non-core food $(B=-0.4)$ and sweetened beverage consumption $(B=-0 \cdot 5)$. By contrast, inverse associations were observed with child control (fruit and vegetables: $B=-1 \cdot 1$; non-core 
foods: $B=0.5$ ), although no relationship to sweet drink intake was seen. Higher levels of monitoring were also related to lower non-core food and sweet drink intake $(B=-0.4$ and -0.5 , respectively). A 1 -point increase in fruit and vegetable score or non-core food score is equivalent to an increase in variety or frequency of consumption of that food group of approximately one type or time each day ${ }^{(26)}$. A 1-point increase in score for the sweet drink scale is approximately equal to an extra sweet drink serving per day ${ }^{(26)}$.

These regressions were also undertaken with an interaction term for fussy eating and the feeding practice. These indicated that fussy eating moderated the associations between fruit and vegetable consumption and both restriction (interaction term $P=0.003$ ) and monitoring (interaction term $P=0.043$ ). This moderation was most pronounced with restriction, where the relationship between increased restriction and greater fruit and vegetable consumption was very strong with fussy eaters $(B=2.9 ; 95 \%$ CI $1.5,4.3 ; P<0.001)$ but not at all present with non-fussy eaters $(B=0 \cdot 1 ; 95 \%$ CI $-0 \cdot 9, \quad 1 \cdot 1$; $P=0 \cdot 873$ ). Monitoring showed a stronger positive (though non-significant) relationship with fruit and vegetable consumption among fussy eaters compared with non-fussy eaters (fussy eaters: $B=1 \cdot 0 ; 95 \% \mathrm{CI}-0 \cdot 1,2 \cdot 2 ; P=0 \cdot 076$; non-fussy eaters: $B=-0 \cdot 4 ; 95 \% \mathrm{CI}-1 \cdot 4,0 \cdot 6 ; P=0 \cdot 459)$.

\section{Discussion}

The present analysis used a comprehensive measure of feeding practices to investigate associations with problem eating behaviours and diet in overweight children. From this it was seen that more structure and oversight of the feeding environment by parents was related to fewer problem eating behaviours by these children, particularly fussy eating. This is contrary to previous studies, which used more limited measures of feeding practices and have suggested that more parental control may be detrimental to a child's diet and eating behaviours ${ }^{(10,11,28)}$.

Parents who guided their child's eating in a healthy way had children who consumed more fruit and vegetables and fewer non-core foods and sweet drinks. Similar negative associations with less healthy foods were also seen with parental monitoring of food intake, with the parents of fussy children monitoring less, which has been shown in previous research ${ }^{(13,15)}$. Results suggest that healthy eating guidance and, in particular, monitoring may have a greater positive effect on the diets of fussy children than non-fussy children or that a lack of these influences has exacerbated or caused fussy eating. Alternatively it may be that with particularly picky children, a reduction in these positive feeding practices has occurred in response to the child's eating behaviours.

Higher levels of parent pressure (urging the child to eat and/or using food as a reward) were reported by parents of fussy children. It seems logical that parents would urge their child to eat if he/she refused food and also that parents might use food as a reward to overcome resistant behaviour. This is also consistent with the currently available literature ${ }^{(11-13)}$.

Perhaps a surprising result was the strong positive association between restriction and fruit and vegetable consumption seen only in fussy eaters. Restriction is a controlling practice where parents limit consumption of unhealthy foods and also the amount of food consumed, which could understandably elicit a conflictive response from the child. This was illustrated by the higher reported levels of restriction in the parents of children classed as fussy. However, the positive relationship with fruit and vegetable intake suggests that if an overweight child who is a picky eater has a parent who limits food intake, then that child's fruit and vegetable consumption is greater than that of a picky child with a parent who does not limit food intake. A 1-point increase in restriction by the parent equates to approximately a 3-point increase in fruit and vegetable score, suggesting an increase in both variety and frequency of fruit and vegetable consumption each day. This would appear to be a meaningful improvement.

Child control was consistently associated with fussy eating behaviours and with a lower intake of fruit and vegetables and a higher intake of non-core foods. Fussy eating is a problem for parents and the associations presented here highlight a lack of structure and control from the parent. However, given the cross-sectional nature of these analyses it is unknown whether this occurs as a response or a contribution to the fussy eating, or if there is an unaccounted confounder.

Eating too quickly and eating too much were related to more restriction and less pressure from parents. Both these parental feeding practices could be either a response to this child eating behaviour or a cause. For example, a parent who restricts food might groom a child to eat quickly and to then be perceived to eat too much. Or it could be that a child who eats too quickly and/or too much requires more restriction from a parent. Eating unhealthy snacks was related to those parental feeding practices that might make the household more conducive to consuming more unhealthy snacks; that is, less healthy eating guidance and monitoring, and more child control.

Children who requested food continuously between meals ate more non-core foods and understandably this frequent requesting was also associated with a higher degree of perceived restriction by the parent. However, there was also less guidance and monitoring, and more child control, suggesting limited structure in the feeding environment, which might leave a child unsure about when and what food will be allowed, leading to more asking and then to more regulation by the parent. An overweight child who continuously asks for food is likely to be stressful for a parent and strategies to reduce this would be helpful, such as having set eating times that the 
whole family is aware of and adheres to; not having highly desirable food available in the home; and having healthy foods available to direct the child towards.

An unusual result is the correlation between parent pressure and sneaking food, which although weak might be picking up a rebellious response by the child to the overt control exhibited by the parent. Future research could explore links between children's behaviour (such as non-compliance) and feeding practices to clarify this theory. Indeed, it may be that training parents in behaviour management techniques results in changes to the feeding practices used and improvement in other aspects, including diet, problem food behaviours and ultimately weight in children ${ }^{(29,30)}$.

Eating for comfort was associated with restriction, which has been seen previously ${ }^{(15)}$. This might indicate that children who comfort-eat are in more need of restrictive feeding practices. While longitudinal evidence has suggested that girls eat more in the absence of hunger if their parents exhibit more restriction at home ${ }^{(31,32)}$, this observation was from an experimental setting where the restriction was removed for a while and therefore is not directly comparable to a parental report of comfort eating in the home environment. Furthermore, restriction was not related to secretive eating behaviours, such as food hiding or sneaking in this sample.

The present analysis of problem food behaviours and feeding practices responds to the need for evidence-based recommendations for how parents feed their children, given that child behaviour is cited as a major barrier. A reasonable sized and diverse sample was used to examine associations between problem food behaviours, dietary intake and parental feeding practices, so that for each analysis there were greater than ten participants per variable. However, it may still be that this sample did not have the power to detect associations, in particular for the possibility of interactions between fussy eating and feeding practices on dietary intake. Furthermore, it is a possibility that some of the significant results may have occurred by chance. This sample consisted of overweight children only, so the results are not generalisable to other populations. However, this is a group of great relevance and these results may be used to inform intervention studies looking to treat overweight in children of this age. Replication of the study in a sample of children of all sizes (not just overweight) might offer a deeper understanding of how feeding practices are related to problem food behaviours and whether these have greater or lesser associations in overweight children. While further longitudinal and experimental research is needed, the study has revealed interesting associations and proposed theories that require testing. Hypotheses to examine include: If fussy eating is treated, does this improve the diets and weight of children? Does more child control of feeding cause or exacerbate fussy food behaviour in overweight children? Does a more structured feeding environment result in fewer requests for food or less fussiness? Is fussy eating related to weight status and/or weight gain? And finally, is child non-compliance (i.e. refusing to eat or behave appropriately with eating) related to feeding practices and dietary intake?

To conclude, associations between parental feeding practices, dietary intake and problem food behaviours exist in overweight children and indicate that a more structured food environment might be advantageous for children of this age.

\section{Acknowledgements}

Financial support: This work was supported by the Health Research Council of New Zealand (grant number HRC 09/087B). The Health Research Council of New Zealand had no role in the design, analysis or writing of this article. Conflict of interest: None. Authorship: R.W.T. is Principal Investigator of the MInT Study. R.W.T. and J.J.H. designed the study; J.J.H. collected and analysed data; J.J.H. wrote the draft manuscript; R.W.T., P.M.L.S. and S.M.W., supervised; all authors contributed to writing of the manuscript. Ethics of human subject participation: Ethical approval was obtained from the Lower South Regional Ethics Committee (LRS/09/09/039) and informed, written consent was obtained from a parent or guardian of all participating children.

\section{References}

1. Barlow SE (2007) Expert committee recommendations regarding the prevention, assessment, and treatment of child and adolescent overweight and obesity: summary report. Pediatrics 120, Suppl. 4, S164-S192.

2. American Academy of Pediatrics Committee on Nutrition (2003) Prevention of pediatric overweight and obesity. Pediatrics 112, 424-430.

3. Dwyer J, Needham L, Simpson JR et al. (2008) Parents report intrapersonal, interpersonal, and environmental barriers to supporting healthy eating and physical activity among their preschoolers. Appl Physiol Nutr Metab 33, $338-346$.

4. Slusser W, Prelip M, Kinsler J et al. (2011) Challenges to parent nutrition education: a qualitative study of parents of urban children attending low-income schools. Public Health Nutr 14, 1833-1841.

5. Power TG, Bindler RC, Goetz S et al. (2010) Obesity prevention in early adolescence: student, parent, and teacher views. J Sch Health 80, 13-19.

6. Slater A, Bowen J, Corsini N et al. (2010) Understanding parent concerns about children's diet, activity and weight status: an important step towards effective obesity prevention interventions. Public Health Nutr 13, 1221-1228.

7. Fulkerson JA, Story M, Neumark-Sztainer D et al. (2008) Family meals: perceptions of benefits and challenges among parents of 8- to 10-year-old children. J Am Diet Assoc 108, 706-709.

8. Hoerr S, Utech AE \& Ruth E (2005) Child control of food choices in Head Start families. J Nutr Educ Behav 37, 185-190. 
9. McKee MD, Maher S, Deen D et al. (2010) Counseling to prevent obesity among preschool children: acceptability of a pilot urban primary care intervention. Ann Fam Med 8, $249-255$.

10. van der Horst K (2012) Overcoming picky eating. Eating enjoyment as a central aspect of children's eating behaviors. Appetite 58, 567-574.

11. Farrow CV, Galloway AT \& Fraser K (2009) Sibling eating behaviours and differential child feeding practices reported by parents. Appetite 52, 307-312.

12. Webber L, Cooke L, Hill C et al. (2010) Associations between children's appetitive traits and maternal feeding practices. J Am Diet Assoc 110, 1718-1722.

13. Powell FC, Farrow CV \& Meyer C (2011) Food avoidance in children. The influence of maternal feeding practices and behaviours. Appetite 57, 683-692.

14. Mascola AJ, Bryson SW \& Agras WS (2010) Picky eating during childhood: a longitudinal study to age 11 years. Eat Behav 11, 253-257.

15. Blissett J, Meyer C \& Haycraft E (2011) The role of parenting in the relationship between childhood eating problems and broader behaviour problems. Child Care Health Dev 37, 642-648.

16. Birch LL, Fisher JO, Grimm-Thomas K et al. (2001) Confirmatory factor analysis of the Child Feeding Questionnaire: a measure of parental attitudes, beliefs and practices about child feeding and obesity proneness. Appetite 36, 201-210.

17. Kenyon DB, Fulkerson JA \& Kaur H (2009) Food hiding and weight control behaviors among ethnically diverse, overweight adolescents. Associations with parental food restriction, food monitoring, and dissatisfaction with adolescent body shape. Appetite 52, 266-272.

18. Savage JS, Haisfield L, Fisher JO et al. (2012) Do children eat less at meals when allowed to serve themselves? Am J Clin Nutr 96, 36-43.

19. Rigal N, Chabanet C, Issanchou S et al. (2012) Links between maternal feeding practices and children's eating difficulties. Validation of French tools. Appetite 58, 629-637.

20. Taylor R, Brown D, Dawson A et al. (2010) Motivational interviewing for screening and feedback and encouraging lifestyle changes to reduce relative weight in 4-8 year old children: design of the MInT study. BMC Public Health 10, 271.

21. Kuczmarski R, Ogden C, Guo S et al. (2002) 2000 CDC growth charts for the United States: Methods and development. Vital Health Stat 11 issue 246, 1-190.

22. Statistics New Zealand (2006) 2006 Census questionnaires. http://www.stats.govt.nz/census/about-2006-census/2006census-questionnaires (accessed May 2012).

23. White P, Gunston J, Salmond C et al. (2008) Atlas of Socioeconomic Deprivation in New Zealand NZDep2006. Wellington: Ministry of Health.

24. Musher-Eizenman D \& Holub S (2007) Comprehensive Feeding Practices Questionnaire: validation of a new measure of parental feeding practices. J Pediatr Psychol 32, 960-972.

25. Haszard JJ, Williams SM, Dawson AM et al. (2013) Factor analysis of the Comprehensive Feeding Practices Questionnaire in a large sample of children. Appetite 62, 110-118.

26. Magarey A, Golley R, Spurrier N et al. (2009) Reliability and validity of the Children's Dietary Questionnaire: a new tool to measure children's dietary patterns. Int J Pediatr Obes $\mathbf{4}$, 257-265.

27. West F \& Sanders M (2009) The Lifestyle Behaviour Checklist: a measure of weight-related problem behaviour in obese children. Int J Pediatr Obes 4, 266-273.

28. Birch LL \& Fisher JO (1998) Development of eating behaviors among children and adolescents. Pediatrics 101, 539-549.

29. West F, Sanders MR, Cleghorn GJ et al. (2010) Randomised clinical trial of a family-based lifestyle intervention for childhood obesity involving parents as the exclusive agents of change. Behav Res Ther 48, 1170-1179.

30. Gerards S, Sleddens EFC, Dagnelie PC et al. (2011) Interventions addressing general parenting to prevent or treat childhood obesity. Int J Pediatr Obes 6, E28-E45.

31. Fisher JO \& Birch LL (2002) Eating in the absence of hunger and overweight in girls from 5 to $7 \mathrm{y}$ of age. Am J Clin Nutr 76, 226-231.

32. Birch LL, Fisher JO \& Davison KK (2003) Learning to overeat: maternal use of restrictive feeding practices promotes girls' eating in the absence of hunger. Am J Clin Nutr 78, 215-220. 